\title{
BRICS-T Ülkelerinde Sağlık Harcamaları Ekonomik Büyümeyi Etkiliyor mu? Ampirik Bir İnceleme
}

\author{
Does Health Expenditures Affect Economic Growth in BRICS-T Countries? An \\ Empirical Investigation
}

Ferhat Şirin SÖKMEN ${ }^{1}$

\begin{abstract}
$\ddot{\mathbf{O z}}$
Amaç: İçsel büyüme teorilerinde, beşeri sermaye ekonomik büyümeyi etkileyen unsurlar arasında yer almaktadır. Beşeri sermaye faktörlerinden biri olan sağlık düzeyindeki artışlar bir yandan, işgücü verimliliğini arttırırken, diğer yandan yaşam süresini arttırarak fiziksel yatırımlardaki artıs yoluyla ekonomik büyüme üzerinde pozitif etki yaratmaktadır. $\mathrm{Bu}$ çalışmada sağlık harcamalarının ekonomik büyümeye etkisi BRICS-T ülkeleri için ele alınmıştır.

Tasarım/Yöntem: 2000-2018 döneminin ele alındığı çalışmada, sağlık harcamalarını temsilen kişi başına düşen sağlık harcamaları, ekonomik büyümeyi temsilen ise sabit fiyatlarla GSYH değişkenleri kullanılmıştır. Uzun dönemli ilişkiyi sınamak amacıyla Westerlund (2008) DH (Durbin-Hausman) Eş Bütünleşme testi ve kısa dönemli ilişkinin varlı̆̆ını test etmek amacıyla Kónya (2006) Bootstrap nedensellik testinden yararlanılmıştır.
\end{abstract}

Bulgular: Westerlund (2008) DH (Durbin-Hausman) Eş Bütünleşme testi sonucunda, sağlık harcamaları ve ekonomik büyüme değişkenleri arasında eş bütünleşme ilişkisinin var olduğu sonucuna ulaşıllırken, Kónya (2006) Bootstrap Nedensellik Test sonuçlarına göre sağlık harcamaları değişkeninden, ekonomik büyümeye doğru nedensellik ilișkisi söz konusu olduğu sonucuna ulaşılmıştır. $\mathrm{Bu}$ sonuçlar, BRICS-T ülkelerinde sağlı odaklı büyüme hipotezinin geçerli olduğunu destekler niteliktedir.

Sinırlılıklar: Çalışmanın temel sınırlılığı örnekleme dahil edilen ülkeler ve 2000-2018 dönemleri olarak belirlenmiștir.

Özgünlük/Değer: Bu çalışmada beşeri sermayenin önemli bir bileșeni olan sağlık harcamalarının ekonomik büyüme üzerindeki etkisi BRICS ülkeleri ve Türkiye için karşılaştırmalı olarak analiz edilmiștir.

Anahtar Kelimeler: Sağlık Harcamaları, Ekonomik Büyüme, BRICS-T

\begin{abstract}
Purpose: Human capital is among the factors affecting economic growth in endogenous growth theories. Increases in health, which is one of the human capital factors, not only increases labor productivity but also has a positive effect on economic growth by increasing life expectancy and increasing physical investments. In this study, the effect of health expenditures on economic growth is discussed for BRICS-T countries.
\end{abstract}

Design/Methodology: Per capita health expenditures representing health expenditures and GDP variables with fixed prices were used to represent economic growth in this study covering the period of 2000-2018. Westerlund (2008) DH (Durbin-Hausman) Cointegration test was applied to test the long-termed relationship; Kónya (2006) Bootstrap causality test was utilized to test the existence of a shortterm relationship.

Findings: Westerlund (2008) DH (Durbin-Hausman) co-integration test results in the conclusion that there is a co-integration relationship between health expenditures and economic growth variables, according to the Kónya (2006) Bootstrap Causality Test results, there is a causality relationship from the health expenditure variable to economic growth. These results support the validity of the health-oriented growth hypothesis in BRICS-T countries.

Limitations: The main limitation of the study was determined as the countries included in the sampling and the period of 2000-2018.

Originality/Value: In this study, the effect of health expenditures, which is an important component of human capital, on economic growth was analyzed comparatively for BRICS countries and Turkey.

Keywords: Health Expenses, Economic Growth, BRICS-T

\footnotetext{
${ }^{1}$ Dr. Öğr. Üyesi, Şırnak Üniversitesi, Cizre Meslek Yüksekokulu, Muhasebe ve Vergi Bölümü, sokmenferhat@sirnak.edu.tr,
} ORCID: 0000-0002-9563-3526 


\section{GİRIŞ}

İçsel büyüme modelleri, beşeri sermayenin ekonomik büyüme ve kalkınmanın belirleyici olduğunu ortaya koymaktadır. Sağlık, sosyoekonomik kalkınmada temel rol oynayan beşeri sermaye faktörlerinden biridir. $\mathrm{Bu}$ nedenle inovasyonu önceleyen bir ekonomi yaratmak için sağlik harcamalarına önem atfedilmesi gerekmektedir (Khan vd., 2015: 640). Bunun yanı sıra; 2019 yılında Çin'de başlayan ve tüm dünya ülkelerini etkisi altına alan Covid-19 pandemisi, sağlığın önemini bir kez daha ortaya koymaktadır. Pandemi ile birlikte sağlıkta yaşanan olumsuz gelişmeler, ekonomide bir taraftan talep yetersizliğini ortaya çıkarırken diğer taraftan arz daralmalarını beraberinde getirmektedir. Arz ve talepte meydana gelen daralmaların birlikte yaşanması ile ortaya çıkan stagflasyon krizi, sağlık ve ekonomi ilişkisinin önemini ortaya koymaktadır.

Sağlık harcamalarındaki artışlar, bir sermaye faktörü olarak kabul edilen sağlık düzeyinde artışa yol açar ve bu durum, işgücü verimliliğinde artışı beraberinde getirerek, gelirlerde ve refah düzeyinde artışa neden olur (Piabuo \& Tieguhong, 2017: 7). Bunun yanında; sağlık harcamalarındaki artışlar ortalama yaşam süresinde artışa neden olmakta ve bu artışlar fiziksel yatırımların artmasını teşvik etmektedir. Fiziksel yatırımlardaki artışlar ise uzun dönemde büyümeyi arttırmaktadır (Akar, 2014: 313). Sağlık harcamalanındaki artış, beşeri sermaye faktörlerinden olan eğitimin verimliliğini de arttırmaktadır. Bunun nedeni ise, sağlıklı insanların, eğitimsel olarak edindikleri bilgi ve becerilerden etkili ve sürekli yararlanacak olmalarıdır (Boachie, 2017: 254). Sağlık harcamalarındaki bu artışın ekonomik büyümede meydana getirdiği canlanma ise literatürde sağlık odaklı büyüme hipotezi olarak adlandırılmaktadır. Sağlık odaklı büyüme hipotezine göre, beşeri sermayenin önemli bir bileşeni olan sağlık düzeyindeki gelişme, emek faktörünün yanı sıra diğer üretim faktörlerinin verimliliğini arttırarak ekonomik büyümeye katkı sağlamaktadır (Atilgan vd., 2017: 567). Diğer taraftan; sağlık sektörünün gelişememesi, ekonomilerde sermayenin verimliliğini olumsuz yönde etkileyerek ekonomik büyümede azalmalara neden olmaktadır (Açc1, 2018: 95).

Sağlik ve ekonomi ilişkisi Covid-19 pandemisi ile birlikte tekrar önem arz eden bir husus haline gelmiştir. Bu çalışmada, sağlık harcamaları ve ekonomik büyüme ilişkisinin BRICS-T ülkeleri için analiz edilmesi amaçlanmaktadır. Literatürde yer alan çalışmalardan yola çıkılarak (Liu vd., 2019; Boachie, 2017, Piabuo \& Tieguhong, 2017, Chen, 2016, Khan vd., 2016, Bakare \& Sanmi, 2011) sağlık düzeyinin ekonomik büyümeyi olumlu yönde etkileyeceği hipotezi BRICS-T ülkeleri için test edilecektir. BRIC ülkeleri (Brezilya, Rusya, Hindistan ve Çin) kısaltması ilk olarak Goldman Sach tarafından ortaya konulmuştur. 2000 yılının sonunda, Brezilya, Rusya, Hindistan ve Çin'in (BRIC) GSYH's1 dünya GSYH'sinin yaklaş1k \%23,3'ü olması ve bu ülkelerin ekonomik büyüme hızlarının gelişmiş ülkelerin ekonomik büyümelerini geride bırakması bu ülkeleri önemli bir ekonomik aktör haline getirmiştir (O'neill, 2001). Ayrıca, sanayi ürünlerinin önemli üreticisi konumunda olan Çin ve Hindistan ile hammadde ve diğer ülkelere enerji tedarik eden Rusya ve Brezilya'nın bir araya gelip ortak bir güç oluşturmaları durumunda dünya ekonomisinin önemli aktörleri haline gelebilecek konuma sahip olmaları, bu ülkelerin bir arada ele alınmasını sağlamıştır. (Özsoylu \& Algan, 2011: 2). BRIC topluluğuna en son katılan ülke ise Güney Afrika'dır. Çalışmada bu ülke grubunun seçilmesinin nedeni ise; bir yandan hammadde tedarik eden, diğer yandan ise sanayi ürünleri üretiminde önemli yere sahip olan bu ülkelerin oluşturduğu bu grupta sağlık harcamalarının ekonomik büyüme üzerinde etkisinin varlığının ortaya konulmak istenmesidir. Türkiye'nin göstermiş olduğu ekonomik performans ile BRICS iş birliği mekanizması üye ülkelerinin ekonomik performansı benzerlikler göstermektedir. Ekonomik performansları nedeniyle "yükselen piyasalar" olarak adlandırılan Güney Kore, Meksika ve Endonezya ve Türkiye'nin de BRICS'e dâhil edilmesi gerektiği düşüncesi hakim olmuştur (Battal \& Akan, 2019: 2). BRICS ülkeleri ve Türkiye'de sağlık harcamaları ve ekonomik büyüme ilişkisinin analiz edildiği bu çalışmada öncelikle ilgili literatüre yer verilmiş olup, daha sonra veri ve metodoloji kısmı açıklanmıştır. Son olarak ampirik analizler neticesinde elde edilen bulgular ortaya konulduktan sonra bu bulguların değerlendirmelerine yer verilmiştir.

\section{LITERATÜR}

Literatür incelendiğinde, ekonomik büyüme ile sağlık harcamaları arasındaki ilişkiyi analiz eden birçok çalışmanın var olduğu görülmektedir. Bu çalışmalardan bazıları sağlık harcamalarının büyüme üzerinde pozitif etkiye sahip olduğunu ortaya koyarken; Liu vd. (2019), Boachie (2017), 
Piabuo ve Tieguhong (2017), Chen (2016), bazı çalışmalarda ise bu etkinin negatif olarak gerçekleştiği sonucuna ulaşılmıştır (Ogundipe \& Lawal, 2011). Sağlık harcamalarının ekonomik büyüme üzerinde negatif etki yaratması ise ele alınan ülkedeki sağlık sektörünün gelişmemiş olması ile açıklanabilmektedir (Tang, 2011: 201).

Çelik (2020), G-20 ülkelerini ele aldığı çalışmasında, kısa dönemde ekonomik büyümenin sağlık harcamalarını etkilediği bulgusuna ulaşmışken, uzun dönemde ise sağlık harcamalarından büyümeye doğru pozitif ve istatistiki olarak anlamlı nedensellik ilişkisinin var olduğu sonucuna ulaşmiştır.

Liu vd. (2019), ekonomik durgunluğun nüfus sağlığı üzerinde olumsuz etkiler yaratabileceğine ilişkin literatürde yer alan görüşü farklı analiz yöntemleriyle ele aldıkları çalışmalarında literatürde yer alan çalışmaları destekleyici nitelikte sonuçlara ulaşmışlardır. MF-VAR ve LF-VAR analiz yöntemlerinin kullanıldığı çalışmada, ekonomik büyüme ve sağlık göstergelerinin karşılıklı olarak birbirlerini etkilediği bulgularına ulaşılmıştır.

Tıraş ve Ağır (2018), yeni nesil panel nedensellik testlerinden yararlandıkları çalışmalarında, OECD ülkelerinde sağlık harcamaları ile gelir arasında nedensellik ilişkisinin var olduğu sonucuna ulaşmışlardır. Çalışmada ayrıca, OECD ülkelerinde gelirde gerçekleşen artışın, en fazla toplam sağlık harcamalarını arttırdığ 1 bulgusuna ulaşılmıştır.

Boachie (2017), sağlık ve ekonomik büyüme ilişkisini Gana için ampirik olarak ele almıştır. 1982-2012 dönemi verilerinin kullanıldığ yararlanılmıştır. Çalışma sonucunda sağlığın kısa ve uzun dönemde ekonomik büyümeyi önemli ölçüde etkilediği bulgularına ulaşılmıştır. Bu bulgular neticesinde kalkınma politikasının sağlık yatırımlarını arttırmayı hedefleyecek şekilde oluşturulması gerekliliği vurgulanmıştır.

Piabuo ve Tieguhong (2017), sağlıklı işgücünün ekonomik büyüme üzerinde pozitif etkiye sahip olduğu görüşünü destekleyici şekilde, CEMAC ülkelerine sağlık harcamaları ile ekonomik büyümenin karşılıklı olarak birbirlerini pozitif yönde etkileyecekleri sonucuna ulaşmışlardır.

Chen (2016), literatürde Brenner hipotezi olarak adlandırılan, sağlık ilerlemesi ve ekonomik büyüme ilişkisini USA ekonomisi için analiz etmiştir. Çalışmada ulaşılan sonuçlar, kısa ve uzun dönemde iki değişken arasında pozitif yönlü bir ilişkinin varlığını ortaya koyarken, uzun vadede negatif yönlü bir ilişkinin var olduğunu destekler niteliktedir.

Khan vd. (2016), Güney Asya ülkelerinde sağlık harcamaları ve ekonomik büyüme ilişkisini panel veri analizi yardımıyla incelemişlerdir. 1995-2012 verilerinin kullanıldığ çalışmada, ekonomik büyümenin sağlık harcamalarını etkilediği sonucuna ulaşılmıştır.

Arslan vd. (2016), sağlık ile kalkınma ilişkisini Hatemi-J nedensellik testi yardımıyla inceledikleri çalışmalarında, sağlık göstergeleri ile kalkınma arasında pozitif yönlü bir ilişki tespit etmişlerdir.

Akar (2014), Türkiye ekonomisinde sağlık harcamaları ile büyüme ilişkisini 2004-2013 dönemi verilerini kullanarak analiz etmiştir. Çalışmada elde edilen analiz sonuçları neticesinde; uzun dönemde sağlık harcamaları ile büyüme değişkenleri arasında istatistiki olarak anlamlı bir ilişkinin var olduğunu, kısa dönemde ise değişkenler arasında anlamlı bir ilişkinin olmadığını ortaya koymaktadır. Tıraşoğlu ve Yıldırım (2012) ise, Türkiye için sağlık harcamaları ile büyüme ilişkisini yapısal kırılmalar altında ele almışlardır. Gregory ve Hansen (1996) nedensellik testi sonucunda değişkenler arasında uzun dönemde anlamlı bir ilişkinin var olduğu ortaya konulmaktadır.

Bakare ve Sanmi (2011), Nijerya ekonomisi için sağlık odaklı büyüme hipotezini ele aldıkları çalışmalarında; sağlık harcamaları ve ekonomik büyüme arasında istatistiki olarak anlamlı ve pozitif bir ilişkinin var olduğunu ortaya koyan sonuçlara ulaşmışlardır. Analizler neticesinde ise politika yapıcılarına sağlık sektörüne ayrılan bütçe miktarının her yıl arttırılması gerektiği önerisinde bulunmuşlardır.

Ogundipe ve Lawal (2011), Nijerya ekonomisi için EKK yöntemini kullanarak ele aldığ1 çalışmasında sağlık harcamalarının ekonomik büyüme üzerinde negatif etkiye sahip olduğu sonucuna ulaşmışlardır. 
Tang (2011), 1970-2009 dönemi verilerini kullanarak, sağlık harcamaları ve büyüme ilişkisini Malezya ekonomisi için analiz ettiği çalışmasında her iki değişken arasında nedensellik ilişkisinin var olduğu sonucuna ulaşmıştır.

Mehrara ve Musai (2011), 11 petrol ihraç eden ülke için sağlık harcamaları ve büyüme ilişkisini analiz ettikleri çalışmalarında ekonomik büyümeden sağlık harcamalarına doğru nedenselliğin olduğu sonucuna ulaşı1ırken, sağlık harcamaları değişkeninden ekonomik büyüme değişkenine doğru nedensellik ilişkisi bulunamamıştır.

Çetin ve Ecevit'in (2010) ele aldıkları çalışmalarında Ogundipe ve Lawal'ın (2011) Nijerya ekonomisi için ulaştığı sonuçları destekleyecek şekilde OECD ülkeleri için sağlık harcamaları ile büyüme arasındaki ilişkinin anlamlı bir ilişki olmadığı sonucuna ulaşılmıştır.

Mayer (2001), sağlık ile ekonomik büyüme ilişkisini 18 Latin Amerika ülkesi için ele aldığ 1 çalışmasında, sağlık harcamalarının eğitim harcamalarına kıyasla ekonomik büyüme üzerinde daha büyük pozitif etki oluşturabileceği sonucuna ulaşmıştır.

\section{VERİ VE METODOLOJI}

Bu çalışmada, ekonomik büyüme ve sağlık harcamaları ilişkisi BRICS-T ülkeleri için analiz edilmiştir. 2000-2018 dönemine ait verilerin kullanıldığı çalışmada, ekonomik büyümeyi temsilen sabit fiyatlarla GSYH değişkeni (ABD Doları cinsinden) kullanılırken, sağlık harcamalarını temsilen kişi başına düşen sağlık harcamaları (SAĞLIK) (ABD Doları cinsinden) değişkeni kullanılmıştır. Değişkenlere ait veriler, Dünya Bankası veri tabanından elde edilmiştir. Çalışmada ekonomik büyüme ve sağlık harcamaları arasındaki ilişkiler analiz edilirken ilk olarak değişkenlere ilişkin yatay kesit bağımlılığı (bundan sonra YKB olarak kullanılacaktır) içerip içermediği ve panel veri modelinde eğim katsayılarının homojenlik/heterojenlik durumları çeşitli testlerle incelenmiştir. Sonrasında YKB ve homojenlik/heterojenlik durumları dikkate alınarak değişkenlerin durağanlık durumları incelenmiştir. Ardından ekonomik büyüme ve sağlık harcamaları arasındaki eşbütünleşme ve nedensellik ilişkileri değişkenlerin yapısına uygun testler kullanılarak analiz edilmiştir.

Bu çalışmada GSYH ve SAĞLIK değişkenlerinde YKB Breusch ve Pagan (1980) $C D_{l m}$, Pesaran (2004) $C D_{l m}$ ve $C D$ ve Pesaran vd. (2008) $L M_{a d j .}$ testleri ile incelenmiştir.

Breusch ve Pagan (1980) $C D_{l m}$ testinde test istatistiği eşitlik (1)'de yer alan formül yardımıyla hesaplanmaktadır (Breusch \& Pagan, 1980: 247).

$$
C D_{l m}(B P, 1980)=T \sum_{i=1}^{N-1} \sum_{j=i+1}^{N} \hat{\rho}_{i j}^{2}
$$

Eşitlik (1)'de $N$ yatay kesit boyutunu, $T$ zaman boyutunu ve $\hat{\rho}$ bireysel en küçük kareler tahmininden elde edilen hata terimlerinin ikili korelasyon katsayısını ifade etmektedir. Pesaran tarafından 2004 yılında Breusch ve Pagan (1980) $C D_{l m}$ testine alternatif olarak iki test geliştirilmiştir. Bunlar Pesaran (2004) $C D_{l m}$ ve $C D$ testleridir. Pesaran (2004) $C D_{l m}$ ve $C D$ test istatistikleri sirasiyla eşitlik (2) ve eşitlik (3)'teki formüller yardımıyla hesaplanmaktadır (Pesaran, 2004: 5).

$$
\begin{aligned}
& C D_{l m}\left(\text { Pesaran, 2004) }=\sqrt{\left(\frac{1}{N(N-1)}\right)} \sum_{i=1}^{N-1} \sum_{j=i+1}^{N}\left(T \hat{\rho}_{i j}^{2}-1\right)\right. \\
& C D\left(\text { Pesaran, 2004) }=\sqrt{\frac{2 T}{N(N-1)}}\left(\sum_{i=1}^{N-1} \sum_{j=i+1}^{N} \hat{\rho}_{i j}\right)\right.
\end{aligned}
$$

Eşitlik 2'deki $C D_{l m}$ testi $\mathrm{T}>\mathrm{N}$ durumunda tutarlı sonuçlar verirken $C D$ testi $\mathrm{N}>\mathrm{T}$ durumunda tutarlı sonuçlar vermektedir (Pesaran, 2004: 5). Pesaran vd. (2008) $L M_{a d j}$ test istatistiği ise eşitlik (4)'teki gibi hesaplanmaktadır (Pesaran vd., 2008: 108).

$$
L M_{a d j}=\sqrt{\left(\frac{2}{N(N-1)}\right)} \sum_{i=1}^{N-1} \sum_{j=i+1}^{N} \hat{\rho}_{i j} \frac{(T-k) \rho_{i j}^{2}-\mu_{T i j}}{\sqrt{v_{T i j}^{2}}}
$$

Eşitlik (4)'te $\mu_{T i j}$ ve $v_{T i j}^{2}$ ise sırasıyla $(T-k) \rho_{i j}^{2}$ 'ya ilişkin tam ortalamayı ve varyansı, $k$ ise açıklayıcı değişken sayısını ifade etmektedir. Her dört teste ilişkin temel hipotez de yatay kesit bağımlılığı yoktur şeklindedir. YKB testleri sonuçları doğrultusunda, değişkenlerde durağanlık 
sınamas1 yapılırken ve değişkenler arasındaki eşbütünleşme ve nedensellik ilişkileri analiz edilirken YKB'nı dikkate alan testler seçilmiştir.

Değişkenler arasındaki ilişkilerin analizinde kullanılan eşbütünleşme ve nedensellik testlerinin seçiminde göz önünde bulundurulan diğer bir unsur ise oluşturulan modellerde eğim katsayılarının homojenlik/heterojenlik durumlarıdır. Çalışmada modellerde eğim katsayılarının homojenlik/heteronejlik durumları Pesaran ve Yagamata (2008) $\tilde{\Delta}$ ve $\tilde{\Delta}_{a d j}$ testleri ile incelenmiştir. $\tilde{\Delta}$ ve $\tilde{\Delta}_{a d j}$ test istatistikleri sırasıyla eşitlik (5) ve (6)'daki gibi hesaplanmaktadır (Pesaran \& Yagamata, 2008: 57).

$\tilde{\Delta}=\sqrt{N}\left(\frac{N^{-1} \tilde{S}-k}{\sqrt{2 K}}\right)$

$\tilde{\Delta}_{a d j}=\sqrt{N}\left(\frac{N^{-1} \tilde{S}-E\left(\tilde{Z}_{i t}\right)}{\sqrt{\operatorname{Var}\left(\tilde{Z}_{i t}\right)}}\right)$

Eşitlik (5) ve (6)'da $\tilde{Z}_{i t}$ sınırlı ortalama varyansa sahip rastgele bağımsız değişkenleri, $\tilde{S}$ düzeltilmiş Swamy istatistiğini, $\operatorname{Var}\left(\tilde{z}_{i t}\right) 2 k(T-K-1) / T+1$ 'yi, $E\left(\tilde{Z}_{i t}\right)$ ise $k$ 'y1 ifade etmektedir (Pesaran \& Yagamata, 2008: 57). Her iki teste ilişkin temel hipotez de eğim katsayılarının homojen olduğu şeklindedir.

Değişkenlere ilişkin durağanlık sınaması gerçekleştirilirken YKB ve homojenite testleri sonuçları dikkate alınmıştır. Aşağıda gerçekleştirilen YKB ve homojenite testleri neticesinde değişkenler arasında YKB görüldügü ve değişkenlerin heterojen yapıya sahip oldukları tespit edildiğinden durağanlık sınamasında ikinci nesil birim kök testlerinden olan Pesaran (2007) CADF ve CIPS testleri kullanılmıştır.

Pesaran (2007) CADF testi veri setinde yer alan her bir birim için birim kök sınaması gerçekleştirmektedir. CADF testi, her bir birim için değişkenlerin birinci farkları ve gecikmeli düzeylerini kullanılarak birimlere ilişkin ortalama ile ADF regresyon modelini genişletmekte ve böylece birimler arasındaki bağımlılığı yok etmektedir. CADF testine ilişkin regresyon modeli eşitlik (7)'deki gibidir (Pesaran, 2007: 269).

$\Delta y_{i t}=a_{i}+b_{i} y_{i, t-1}+c_{i} \bar{y}_{t-1}+d_{i} \Delta \bar{y}_{t}+e_{i t}$

Eşitlik (7)'de, $a_{i}, b_{i}$ ve $c_{i}$ sabit etki katsayılarını, $e_{i t}$ birimlere özgü hatayı, $y_{i}$ belirli bir yoğunluk fonksiyonuna sahip başlangıç değerlerini, $\bar{y}_{t}$ ise tüm gözlemlerin $t$ zamandaki ortalamasını ifade etmektedir (Demir \& Görür, 2020:23). Eşitlik (8)'den de görüleceği gibi her bir birim için hesaplanan CADF test istatistik değerinin aritmetik ortalaması alınarak panel bazında birim kök testi sınamasında kullanılan CIPS test istatistiği elde edilmektedir (Pesaran, 2007: 278).

$C I P S=\frac{1}{N} \sum_{i=1}^{N} C A D F_{i}$

CADF ve CIPS istatistiklerinin Pesaran (2007) çalışmasında verilen kritik tablo değerlerinden küçük gerçekleşmesi ilgili değiş̧kenin durağan olduğuna işaret etmektedir (Pesaran, 2007: 274-281).

Çalışmada ekonomik büyüme ve sağlık harcamaları arasındaki uzun dönemli eşbütünleşme ilişkisi YKB'nı ve heterojenik tahmini dikkate alan eşbütünleşme testlerinden olan Westerlund (2008) DH (Durbin-Hausman) testi ile analiz edilmiştir. DH testi için tek şart, eşbütünleşme modelinde yer alan bağımlı değişkenin düzeyde durağan olmamasıdır. DH testi bağımsız değişkenin ise düzeyde veya birinci farkında durağan olmasına izin vermektedir (Westerlund, 2008: 205). DH testi otoregresif parametrenin heterojen olduğunu varsayan $\mathrm{DH}_{g}$ ve otoregresif parametrenin homojen olduğunu varsayan $D H_{p}$ iki istatistik içermektedir. $D H_{g}$ test istatistiği eşitlik (9)'da $D H_{p}$ ise eşitlik (10)'da yer alan formüller ile hesaplanmaktadır.

$$
\begin{aligned}
& D H_{g}=\sum_{i=1}^{n} \hat{S}_{i}\left(\tilde{\phi}_{i}-\hat{\phi}_{i}\right)^{2} \sum_{t=2}^{T} \hat{e}_{i t-1}^{2} \\
& D H_{p}=\hat{S}_{n}(\tilde{\phi}-\hat{\phi})^{2} \sum_{i=1}^{n} \sum_{t=2}^{T} \hat{e}_{i t-1}^{2}
\end{aligned}
$$

Her iki teste ilişkin temel hipotez de değişkenler arasında uzun dönem eşbütünleşme ilişkisi yoktur şeklindedir. Westerlund (2008) DH testi sonuçları Tablo 4'te yer almaktadır. 
Çalışmada ekonomik büyüme ve sağlık harcamaları arasındaki nedensellik ilişkisi YKB'nı ve heterojenik tahmini dikkate alan nedensellik testlerinden olan Kónya (2006) Bootstrap nedensellik testi ile analiz edilmiştir. Kónya (2006) Bootstrap nedensellik testi, serilerin YKB içermesi ve eğim katsayılarının heterojen olması durumlarında tutarlı sonuçlar veren ve analizden önce birim kök ve eşbütünleşme analizlerini gerektirmeyen bir nedensellik testidir (Kónya, 2006: 991). Test değişkenler arasındaki nedensellik ilişkisi tahmininde Seemingly Unrelated Regression (SUR) ve Wald metodlarına dayanmaktadır (Kónya, 2006: 979). İki değişkenli Kónya (2006) Bootstrap nedensellik modeli eşitlik (11) ve (12)'deki gibidir (Kónya, 2006: 981).

$$
\begin{aligned}
& y_{1, t}=\alpha_{1,1}+\sum_{l=1}^{m l y_{1}} \beta_{1,1, l} y_{1, t-1}+\sum_{l=1}^{m l x_{1}} \gamma_{1,1, l} x_{1, t-1}+\varepsilon_{1,1, t} \\
& y_{2, t}=\alpha_{1,2}+\sum_{l=1}^{m l y_{1}} \beta_{1,2, l} y_{2, t-1}+\sum_{l=1}^{m l x_{1}} \gamma_{1,2, l} x_{2, t-1}+\varepsilon_{1,2, t} \\
& \vdots \quad \vdots \quad \vdots \quad \vdots \quad \vdots \quad \vdots \\
& y_{N, t}=\alpha_{1, N}+\sum_{l=1}^{m l y_{1}} \beta_{1, N, l} y_{N, t-1}+\sum_{l=1}^{m l x_{1}} \gamma_{1, N, l} x_{N, t-1}+\varepsilon_{1, N, t}
\end{aligned}
$$

ve

$$
\begin{aligned}
& x_{1, t}=\alpha_{2,1}+\sum_{l=1}^{m l y_{2}} \beta_{2,1, l} y_{1, t-1}+\sum_{l=1}^{m l x_{2}} \gamma_{2,1, l} x_{1, t-1}+\varepsilon_{2,1, t} \\
& x_{2, t}=\alpha_{2,2}+\sum_{l=1}^{m l y_{2}} \beta_{2,2, l} y_{2, t-1}+\sum_{l=1}^{m l x_{2}} \gamma_{2,2, l} x_{2, t-1}+\varepsilon_{2,2, t}
\end{aligned}
$$

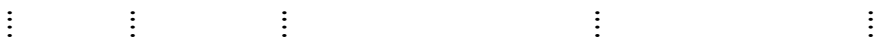

$$
\begin{aligned}
& x_{N, t}=\alpha_{2, N}+\sum_{l=1}^{m l y_{2}} \beta_{2, N, l} y_{N, t-1}+\sum_{l=1}^{m l x_{2}} \gamma_{2, N, l} x_{N, t-1}+\varepsilon_{2, N, t}
\end{aligned}
$$

Eşitlik (11) ve eşitlik (12)'de $y$ GSYH'1, $x$ SAĞLIK'1, $t$ zamanı, $N$ ise ülkeleri ifade etmektedir. Kónya (2006) Bootstrap nedensellik testine ilişkin temel hipotez bağımsız değişkenden bağımlı değişkene doğru bir nedensellik ilişkisi yoktur şeklindedir.

\section{AMPIRIKK SONUÇLAR}

Panel veri analizlerinde, analizlere başlanılmadan önce yatay kesit bağımlılı̆̆ını ortaya koyan testlerin yapılması gerekmektedir. Bunun nedeni yatay kesit varlığının söz konusu olduğu durumlarda, bir ülkede gerçekleşen iktisadi şoklardan diğer ülkelerin etkilenmesi durumu gerçekleşmektedir. Bu nedenle önce yatay kesit bağımlılığı durumunun ortaya konulması gerekmektedir. YKB'nin varlığı net olarak ortaya konulduktan sonra kullanılacak birim kök ve diğer testler doğru şekilde belirlenebilmektedir. YKB testlerine ilişkin sonuçlar Tablo 1'deki gibidir.

Tablo 1: YKB Test Sonuçları

\begin{tabular}{ccc}
\hline Constant & GSYH & SAĞLIK \\
\hline$C D_{l m}(\mathrm{BP}, 1980)$ & $39.737(0.00)^{\mathrm{x}}$ & $35.649(0.00)^{\mathrm{x}}$ \\
\hline$C D_{l m}($ Pesaran, 2004) & $4.516(0.00)^{\mathrm{x}}$ & $3.770(0.00)^{\mathrm{x}}$ \\
\hline$C D($ Pesaran, 2004) & $-2.466(0.007)^{\mathrm{x}}$ & $-1.967(0.025)^{\mathrm{y}}$ \\
\hline$L M_{a d j}(\mathrm{PUY}, 2008)$ & $0.104(0.459)$ & $1.561(0.059)^{\mathrm{z}}$ \\
\hline
\end{tabular}

Not: $\mathrm{x}, \mathrm{y}$ ve $\mathrm{z}$ değerleri sırasıyla $0,01.0,05$ ve 0,10 anlamlılık düzeylerinde olasılık değerlerini göstermektedir.

Çalışmanın veri setinin 19 dönem ve 6 yatay kesit boyutu içermesinden dolayı $\mathrm{T}>\mathrm{N}$ durumunda tutarlı sonuçlar veren $C D_{l m}$ (Breusch \& Pagan, 1980) ve $C D_{l m}$ (Pesaran, 2004) testleri sonuçları dikkate alınmıştır. Tablo 1'de görüleceği üzere GSYH ve SAĞLIK değişkenlerine ait $C D_{l m}$ (Breusch \& Pagan, 1980) ve $C D_{l m}$ (Pesaran, 2004) olasıllk değerleri 0.01'den küçük gerçekleşmiştir. $C D_{l m}$ (Breusch \& Pagan, 1980) ve $C D_{l m}$ (Pesaran, 2004) testlerine ilişkin sonuçlar hem GSYH hem de SAĞLIK değişkenlerinin ilgili dönemde yatay kesit bağımlılı̆̆ 1 içerdiğini işaret etmektedir. Bu durum, ekonomik büyüme ve sağlık harcamaları özelinde yüksek düzeyde küreselleşme ve uluslararası ticaret ve finansal entegrasyon gibi nedenlerle BRICS-T ülkelerinde bir ülkeyi etkileyen bir şokun diğer ülkeleri de etkileyebildiği anlamına gelmektedir. 
Tablo 2: Homojenite Testleri

\begin{tabular}{ccc}
\hline & Statistic & p-value \\
\hline $\begin{array}{ccc}\text { Homogeneity tests: } \\
\tilde{\Delta}\end{array}$ & 16.867 & $0.00^{\mathrm{x}}$ \\
\hline$\tilde{\Delta}_{a d j}$ & 18.294 & $0.00^{\mathrm{x}}$ \\
\hline
\end{tabular}

Not: Regresyon modeli GDP ${ }_{\mathrm{it}}=\alpha_{\mathrm{i}}+\beta_{1 \mathrm{i}} \mathrm{HLTH}+\varepsilon_{\mathrm{it}}$. $\mathrm{x}$, y ve z değerleri sırasıyla $0,01,0,05$ ve 0,10 anlamlılık düzeylerinde olasılık değerlerini göstermektedir.

Tablo 2 homojenite test sonuçlarını göstermektedir. Tablo 2 'de yer alan $\widetilde{\Delta}$ ve $\tilde{\Delta}_{\text {adj }}$ test istatistikleri ve olasılık değerleri incelendiğinde her iki test sonucunda da olasılık değerlerinin \%10 anlamlılık düzeyinde analmlı olduğu ve serilerin heterojen yapıya sahip oldukları görülmektedir. Homojenite testleri doğrultusunda eşbütünleşme ve nedensellik analizlerinde heterojen tahmini dikkate alan yöntemlerinin kullanılması durumu söz konusudur.

Tablo 3: CADF ve CIPS Birim Kök Testi Sonuçları

\begin{tabular}{lcccccccc}
\hline \multirow{2}{*}{ Düzey Değer } & \multicolumn{4}{c}{ GSYH } & \multicolumn{2}{c}{ SAĞLIK } \\
\cline { 2 - 10 } & \multicolumn{2}{c}{ Sabit } & \multicolumn{2}{c}{ Sabit ve Trend } & \multicolumn{2}{c}{ Sabit } & \multicolumn{2}{c}{ Sabit ve Trend } \\
\cline { 2 - 10 } & Lag & CADF & Lag & CADF & Lag & CADF & Lag & CADF \\
\hline Brezilya & 1 & -1.458 & 1 & -2.978 & 1 & -2.158 & 1 & -4.345 \\
\hline Rusya & 1 & -2.622 & 1 & -2.211 & 1 & -3.085 & 1 & -5.359 \\
\hline Hindistan & 1 & -0.562 & 1 & -2.954 & 1 & 0.266 & 1 & -3.192 \\
\hline Çin & 1 & -2.634 & 1 & -2.374 & 1 & -1.789 & 1 & -1.221 \\
\hline Güney Afrika & 1 & -1.105 & 1 & -3.309 & 1 & -4.096 & 1 & -3.991 \\
\hline Türkiye & 1 & -0.980 & 1 & -2.432 & 1 & 0.105 & 1 & -1.342 \\
\hline Panel CIPS & & -1.560 & & -1.710 & & -1.793 & & -2.242 \\
\hline
\end{tabular}

\begin{tabular}{lcccccccc}
\hline \multirow{2}{*}{ Birinci Fark } & \multicolumn{4}{c}{ GSYH } & \multicolumn{2}{c}{ Sabit } & \multicolumn{2}{c}{ Sabit ve Trend } \\
\cline { 2 - 10 } & \multicolumn{2}{c}{ Sabit } & \multicolumn{2}{c}{ Sabit ve Trend } & \multicolumn{2}{c}{ CaIK } \\
\cline { 2 - 10 } & Lag & CADF & Lag & CADF & Lag & CADF & Lag & CADF \\
\hline Brezilya & 1 & -2.336 & 1 & -1.870 & 1 & -2.820 & 1 & -3.297 \\
\hline Rusya & 1 & -2.633 & 1 & -1.200 & 1 & -5.346 & 1 & -4.325 \\
\hline Hindistan & 1 & -3.552 & 1 & -1.892 & 1 & -4.360 & 1 & -5.253 \\
\hline Çin & 1 & -1.599 & 1 & -1.914 & 1 & -1.331 & 1 & -1.341 \\
\hline Güney Afrika & 1 & -4.751 & 1 & -3.362 & 1 & -3.911 & 1 & -3.588 \\
\hline Türkiye & 1 & -2.479 & 1 & -1.144 & 1 & -1.448 & 1 & -2.052 \\
\hline Panel CIPS & & -2.892 & & -2.897 & & -3.203 & & -3.309
\end{tabular}

Not: Sabitli model için kritik değerler: CADF; \%1 için - $4.35, \% 5$ için $-3.43, \% 10$ için -3.00 , CIPS; \%1 için -2.60, \%5 için - $2.34, \% 10$ için 2.21. Sabitli ve trendli model için kritik değerler: CADF; $\% 1$ için $-4.97, \% 5$ için $-3.99, \% 10$ için -3.55 , CIPS; $\% 1$ için $-3.15, \% 5$ için -2.88 , $\% 10$ için -2.74

Tablo 3, CADF ve CIPS durağanlık testi sonuçlarını göstermektedir. Tablo 3'de yer alan sonuçlar incelendiğinde, düzeyde gerçekleştirilen birim kök analizi sonucunda hem GSYH hem de SAĞLIK değişkenlerine ilişkin CIPS test istatistiklerinin hem sabitli hem de sabitli ve trendli modellerde $\% 1, \% 5$ ve $\% 10$ anlamlılık düzeyi kritik değerlerinden daha yüksek gerçekleştiği görülmektedir. Söz konusu bulgular değişkenlerin düzeyde durağan olmadığını işaret etmektedir. serilerin birinci farklarında gerçekleştirilen birim kök analizi sonucunda ise, hem GSYH hem de SAĞLIK değişkenlerine ilişkin CIPS test istatistiklerinin hem sabitli hem de sabitli ve trendli modellerde $\% 1, \% 5$ ve $\% 10$ anlamlılık düzeyi kritik değerlerinden daha düşük gerçekleştiği görülmektedir. Söz konusu bulgular değişkenlerin birinci farklarında durağanlaştığını (I(1)) işaret etmektedir.

Tablo 4: Westerlund (2008) DH Eşbütünleşme Testi Sonuçları

\begin{tabular}{lcccc}
\hline & \multicolumn{2}{c}{ Sabit } & \multicolumn{2}{c}{ Sabit ve Trend } \\
\hline Testler & Test İstatistiği & $\begin{array}{c}\text { Asimptotik } \\
\text { p değeri }\end{array}$ & Test İstatistiği & $\begin{array}{c}\text { Asimptotik } \\
\text { p değeri }\end{array}$ \\
\hline$D H_{g}$ & -1.674 & $0.047^{* *}$ & -1.749 & $0.040^{* *}$ \\
\hline$D H_{p}$ & -0.654 & 0.256 & -0.818 & 0.207 \\
\hline
\end{tabular}

Westerlund (2008) DH testi sonuçları Tablo 4'te yer almaktadır. YKB'nı dikkate alan eş bütünleşme testi olan Westerlund (2008) DH (Durbin-Hausman) testinde, paneldeki betalar homojen 
ise panel istatistik değerleri $\left(D H_{p}\right)$ incelenirken, heterojen ise group istatistik değerleri $\left(D H_{g}\right)$ incelenir. Olasılık değeri 0.05 'ten düşükse eşbütünleşme ilişkisinin var olduğu kabul edilmektedir. Yapılan analizlerde panel bazında heterojenlik söz konusu olduğundan $D H_{g}$ istatistik ve olasılık değerleri dikkate alınarak değerlendirme yapılmıştır. Sabitli ve sabit ile trendli modellerde $D H_{g}$ istatistiklerine ilişkin olasılık değerleri 0.05 'ten düşüktür. Dolayısıyla GSYH ve SAĞLIK değişkenleri arasında uzun dönem eşbütünleşme ilişkisi olduğu söylenebilir. Eşbütünleşme analizi sonuçları, ekonomik büyüme ve sağlık harcamalarının uzun dönemde eşbütünleşik hareket ettiklerini işaret etmektedir.

Tablo 5: Kónya (2006) Bootstrap Nedensellik Test Sonuçları

\begin{tabular}{|c|c|c|c|c|c|c|c|c|c|c|}
\hline \multicolumn{6}{|c|}{ SAĞLIK=>GSYH } & \multicolumn{5}{|c|}{ GSYH=>SAĞLIK } \\
\hline \multirow{2}{*}{ Ülkeler } & \multirow{2}{*}{ Wald } & \multirow{2}{*}{ Boot-pval } & \multicolumn{3}{|c|}{ Critical Values } & \multirow{2}{*}{ Wald } & \multirow{2}{*}{ Boot-pval } & \multicolumn{3}{|c|}{ Critical Values } \\
\hline & & & $\% 1$ & $\% 5$ & $\% 10$ & & & $\% 1$ & $\% 5$ & $\% 10$ \\
\hline Brezilya & 13.120 & 0.455 & 48.136 & 32.621 & 26.310 & 2.298 & 0.997 & 56.415 & 36.066 & 29.555 \\
\hline Rusya & 0.122 & 0.991 & 65.776 & 39.803 & 29.020 & 1.578 & 0.990 & 60.443 & 39.647 & 32.156 \\
\hline Hindistan & 5.165 & 0.048 & 9.313 & 5.068 & 3.484 & 15.831 & 0.677 & 70.800 & 48.134 & 39.333 \\
\hline Çin & 43.15 & 0.000 & 11.401 & 5.624 & 3.621 & 24.515 & 0.015 & 26.244 & 19.337 & 16.418 \\
\hline Güney Afrika & 6.745 & 0.203 & 24.089 & 13.588 & 10.009 & 3.388 & 0.819 & 27.439 & 19.401 & 15.161 \\
\hline Türkiye & 2.632 & 0.155 & 7.107 & 4.354 & 3.264 & 0.896 & 0.836 & 15.403 & 10.033 & 7.917 \\
\hline Panel Fisher & 31.634 & 0.002 & & & & 10.018 & 0.614 & & & \\
\hline
\end{tabular}

Kónya (2006) Bootstrap nedensellik testi sonuçları Tablo 5'te yer almaktadır. Kónya (2006) Bootstrap nedensellik testine sonucunda panel bazında sağlık harcamalarından ekonomik büyümeye doğru nedensellik ilişkisini ifade eden modele ilişkin Wald test istatistiğinin $\% 1, \% 5$ ve $\% 10$ anlamlılık düzeyi kritik değerlerinden yüksek gerçekleştĭgi ve modele ilişkin Bootstrap olasılık değerinin ise 0.002 olarak gerçekleştiği tespit edilmiştir. Dolayısıyla BRICS-T ülkeleri için panel bazında sağlık harcamalarındaki değişimlerin ekonomik büyümedeki değişimlerin nedeni olduğu söylenebilir. Sağlık harcamalarındaki artışlar, bir taraftan bireylerin yaşam beklentisini ve kalitesini artırırken, diğer taraftan sağlık sektörüne yapılan yatırımlar, teknolojik ilerleme yoluyla ekonomik büyümeyi uyarmaktadır (Akar, 2014: 311).

Panel bazında ekonomik büyümeden sağlık harcamalarına doğru nedensellik ilişkisini ifade eden modele ilişkin Wald test istatistiğinin $\% 1$ ve $\% 5$ anlamlılık düzeyi kritik değerlerinden düşük gerçekleştiği ve modele ilişkin Bootstrap olasılık değerinin ise 0.614 olarak gerçekleştiği tespit edilmiştir. Dolayısıyla BRICS-T ülkeleri için panel bazında ekonomik büyümedeki değişimlerin sağlık harcamalarındaki değişimlerin nedeni olmadığg söylenebilir.

\section{SONUC}

Bu çalışmada BRICS-T ülkelerinde 2000-2018 dönemi verileri kullanılarak panel veri analizi tekniklerinden yararlanılarak sağlı harcamaları ve ekonomik büyüme etkisi ampirik olarak analiz edilmiştir. Serilerin durağanlıkları tespit edilmeden önce yatay kesit bağımlılı̆g 1 testi ile ele alınan ülkelerin herhangi birinde gerçekleşen iktisadi bir şokun diğer ülkeleri etkileyip etkilemediği analiz edilmiştir. Analizler neticesinde YKB'nın var olduğu sonucuna ulaşılmıştır. Bu husus, BRICS-T ülkelerinde sosyal ve ekonomik etkileşimlerin var olduğunu ortaya koymaktadır. Serilerin birim kök içerip içermediğini tespit etmek amacıyla YKB'nı dikkate alan CADF ve CIPS birim kök testleri uygulanmıştır. Analizler neticesinde serilerin düzey değerlerinde birim kök içerdikleri, birinci farkları alındığında ise serilerin durağanlaştıkları bulgularına ulaşılmıştır. Pesaran ve Yagamata (2008), Delta ve Delta adj. testleri ile yapılan homojenite araştırmasında, heterojen tahmine dayalı eşbütünleşme yöntemlerinin kullanılması gerekliliği ortaya çıkmıştır. YKB'nı dikkate alan ve heterojen tahmine dayalı eş bütünleşme testi olan Westerlund (2008) DH (Durbin-Hausman) Eş Bütünleşme testi sonucunda, sağlık harcamaları ile ekonomik büyüme değişkenleri arasında eş bütünleşme ilişkisinin var olduğu sonucuna ulaşılmıştır. Kónya (2006) Bootstrap Nedensellik Test nedensellik test sonuçlarına göre sağlık harcamaları değişkeninden, büyümeye doğru nedensellik ilişkisi söz konusu iken, büyümeden sağlık harcamalarına doğru nedensellik ilişkisi söz konusu değildir. Analizler neticesinde elde edilen sonuçlar, Boachie (2017), Chen (2016), Liu vd. (2019), Piabuo ve Tieguhong (2017) ve Tang (2011)'ın elde ettiği sonuçları destekler şekilde sağlık harcamalarının ekonomik büyümeyi etkilediğini ortaya koymaktadır. 
Beşeri sermayenin önemli belirleyicilerinden biri olan sağlığın ekonomik büyümeye olumlu katkı sağlaması nedeni ile sağlık harcamalarının ve sağlık sektörüne yapılan yatırımların artırılması önem arz etmektedir. Bununla birlikte, sağlık sektörüne yapılacak yatırımların inovasyonu öncelemesi ekonomik büyümeye katkı sağlayacaktır.

Etik Beyan: Bu çalışmada "Etik Kurul” izini alınmasını gerektiren bir yöntem kullanılmamıştır.

Ethics Statement: In this study, no method requiring the permission of the "Ethics Committee" was used.

\section{KAYNAKÇA}

Açc1, Y. (2018). Upon testing the health-oriented growth hypothesis for selected OECD countries. Empirical Studies on Growth. Gazi Kitabevi.

Akar, S. (2014). Türkiye'de sağlık harcamaları, sağlık harcamalarının nisbi fiyatı ve ekonomik büyüme arasındaki ilişkinin incelenmesi. Yönetim ve Ekonomi: Celal Bayar Üniversitesi İktisadi ve İdari Bilimler Fakültesi Dergisi, 21(1), 311-322. https://doi.org/10.18657/yecbu.70940

Arslan, İ., Eren, M. V., \& Kaynak, S. (2016). Sağlık ile kalkınma arasındaki ilişkinin asimetrik nedensellik analizi. Dokuz Eylül Üniversitesi İktisadi İdari Bilimler Fakültesi Dergisi, 31(2), 287-310. https://doi.org/10.24988/deuiibf.2016312535

Atilgan, E., Kilic, D., \& Ertugrul, H. M. (2017). The dynamic relationship between health expenditure and economic growth: Is the health-led growth hypothesis valid for Turkey?. The European Journal of Health Economics, 18(5), 567-574. https://doi: 10.1007/s10198-016-0810-5

Bakare, A. A., \& Sanmi O. (2011). Health care expenditure and economic growth in Nigeria: An empirical study. Journal of Emerging Trends in Economics and Management Sciences, 2(2), 8387. https://journals.co.za/doi/pdf/10.10520/EJC133895

Battal, T., \& Ercan, A. (2019). BRICS ülkeleri ile Türkiye'nin performans ve potansiyel kriterleri çerçevesinde değerlendirilmesi. Beykoz Akademi Dergisi, 7(1), 1-35. https://doi.org/10.14514/BYK.m.26515393.2019.7/1.1-35

Boachie, M. K. (2017). Health and economic growth in Ghana: An empirical investigation. Fudan Journal of the Humanities and Social Sciences, 10(2), 253-265. https://doi.org/10.1007/s40647016-0159-2

Breusch, T. S., \& Pagan, A. R. (1980). The lagrange multiplier test and its applications to model specification in econometrics. Review of Economic Studies, 47(1), 239-253. https://www.jstor.org/stable/pdf/2297111.pdf

Chen, W. Y. (2016). Health progress and economic growth in the USA: The continuous wavelet analysis. Empirical Economics, 50(3), 831-855. https://doi.org/10.1007/s00181-015-0955-6

Çelik, A. (2020). G20 ülkelerinde sağlık harcamalarının ekonomik büyüme üzerindeki etkisinin analizi. Yönetim ve Ekonomi, 27(1), 1-20. https://doi.org/10.18657/yonveek.594695

Çetin, M., \& Ecevit, E. (2010). Sağlık harcamalarının ekonomik büyüme üzerindeki etkisi: OECD ülkeleri üzerine bir panel regresyon analizi. Doğuş Üniversitesi Dergisi, 11(2) ,166-182. http://journal.dogus.edu.tr/index.php/duj/article/view/16/30

Demir, Y., \& Görür, Ç. (2020). OECD ülkelerine ait çeşitli enerji tüketimleri ve ekonomik büyüme arasındaki ilişkinin panel eşbütünleşme analizi ile incelenmesi. Journal of Econometrics and Statistics, 32, 15-33. https://doi.org/10.26650/ekoist.2020.32.0005

Khan, H. N., Khan, M. A., Razli, R. B., Shehzada, G., Krebs, K. L., \& Sarvghad, N. (2016). Health care expenditure and economic growth in SAARC countries (1995-2012): A panel causality analysis. Applied Research in Quality of Life, 11(3), 639-661. https://doi.org/10.1007/s11482015-9385-Z 
Kónya, L. (2006). Exports and growth: Granger causality analysis on OECD countries with a panel data approach. Economic Modelling, 23, 978-992. https://doi.org/10.1016/j.econmod.2006.04.008

Liu, Y. H., Chang, W. S., \& Chen, W. Y. (2019). Health progress and economic growth in the United States: The mixed frequency VAR analysis. Quality \& Quantity, 53(4), 1895-1911. https://doi.org/10.1007/s11135-019-00847-z

Mayer, D. (2001). The long-term impact of health on economic growth in Latin America. World Development, 29(6), 1025-1033. https://doi.org/10.1016/S0305-750X(01)00026-2

Mehrara, M., \& Musai, M. (2011). Granger causality between health and economic growth in oil exporting countries. Interdisciplinary Journal of Research in Business, 1(8), 103-108. http://journaldatabase.info/articles/granger_causality_between_health.html

Ogundipe, M. A., \& Lawal, N. A. (2011). Health expenditure and Nigerian economic growth. European Journal of Economics, Finance and Administrative Sciences, 30, 125-129. https://www.academia.edu/532447/Health_Expenditure_and_Nigerian_Economic_Growth

O'neill, J. (2001). Building better global economic BRICs. Global Economics, 66, 1-16. https://www.goldmansachs.com/insights/archive/archive-pdfs/build-better-brics.pdf

Özsoylu, A. F., \& Algan, N. (2011). Dünya ekonomisinin yeni aktörleri: BRIC: Brezilya-RusyaHindistan-Çin. Karahan Kitabevi.

Pesaran, M. H. (2004). General diagnostic tests for cross section dependence in panels. Cambridge Working Papers in Economics, 435, 1-39.

Pesaran, M. H. (2007). A simple panel unit root test in the presence of cross-section dependence. Journal of Applied Econometrics, 22, 265-312. https://doi.org/10.1002/jae.951

Pesaran, M. H., Ullah, A., \& Yamagata, T. (2008). A bias adjusted LM test of error cross section independence. Econometrics Journal, 11, 105-127. https://doi.org/10.1111/j.1368423X.2007.00227.X

Pesaran, M. H., \& Yamagata, T. (2008). Testing slope homogeneity in large panels. Journal of Econometrics, 142, 50-93. https://doi.org/10.1016/j.jeconom.2007.05.010

Piabuo, S. M., \& Tieguhong, J. C. (2017). Health expenditure and economic growth-a review of the literature and an analysis between the economic community for central African states (CEMAC) and selected African countries. Health Economics Review, 7(1), 23. https://doi: 10.1186/s13561$\underline{017-0159-1}$

Şen A., \& Bingöl, N. (2018). Sağlık harcamaları ve ekonomik büyüme ilişkisi: Türkiye örneği. Akademik Yaklașımlar $\quad$ Dergisi, 9(1), 89-106. https://dergipark.org.tr/tr/pub/ayd/issue/37781/436223

Tang, C. F. (2011). Multivariate granger causality and the dynamic relationship between health care spending, income and relative price of health care in Malaysia. Hitotsubashi Journal of Economics, 199-214. http://hermes-ir.lib.hit-u.ac.jp/hermes/ir/re/22028/HJeco0520201990.pdf

Tıraş, H. H., \& Ağır, H. (2018). OECD ülkelerinde sağlık harcamaları ve ekonomik büyüme ilişkisi: Panel nedensellik analizleri. Siyaset, Ekonomi ve Yönetim Araştırmaları Dergisi, 6(4), 13-29. https://dergipark.org.tr/tr/download/article-file/1021343

Tıraşoğlu, M., \& Yıldırım, B. (2012). Yapısal kırılma durumunda sağlık harcamaları ve ekonomik büyüme ilişkisi: Türkiye üzerine bir uygulama. Ejovoc (Electronic Journal of Vocational Colleges), 2(2), 111-117. https://doi.org/10.1501/OTAM_0000000515

Westerlund, J. (2008). Panel cointegration tests of the fisher effect. Journal of Applied Econometrics, 23, 193-233. https://doi.org/10.1002/jae.967 